\section{Relaçóes agrárias na Antiguidade: campo de testes ou berço da sociologia weberiana?}

Max WEBER. Max Weber Gesamtausgabe Band I/6: Zur Sozial - und Wirtschaftsgeschichte des Altertums. Schriften und Reden (1893-1908). Tübingen, Mohr Siebeck, 2006. 975 páginas.

\section{Sérgio da Mata}

Não existe uma sociologia da sociologia weberiana. Tão logo o sociólogo passa a devotar esforços à análise, à reconstrução e à interpretação da obra de Max Weber, mais ele se afasta de um enfoque propriamente "sociológico" (como o da sociologia do conhecimento, por exemplo). Ao se autodefinir como uma ciência para a qual o caso singular não passa de um resíduo, ela se mantém desaparelhada para dar conta da obra daquele que é o mais famoso dos seus pais fundadores. De fato, qualquer que seja a disciplina de origem do intérprete, o que de mais relevante se tem publicado sobre Weber nas últimas décadas está norteado, fundamentalmente, por três enfoques: o hermenêutico, o filológico e o da história das ideias. Em outras palavras, não há uma sociologia compreensiva da sociologia compreensiva. E por uma simples razão: ela não constitui um instrumental heurístico e teórico adequado para compreender a si própria. Como observou Mario Rainer Lepsius, um dos organizadores-chefe da edição crítica das obras de Weber, "a sociologia, como ciência do presente, tem memória curta e está inclinada a encurtar temporalmente o contexto de explicação" (Lepsius, 2005, p. 38). Ampliar o contexto de explicação para todo aquele que estiver interessado em se embrenhar no pensamento e nos escritos de Weber significa fazer história, e história das ideias.

De que forma pode esta disciplina contribuir para uma adequada compreensão e explicação do sociological turn do "mito de Heidelberg"? Eis aí uma das questóes mais controversas no âmbito dos Weber Studies.

Num dado momento de sua vida, Weber dá-nos a impressão de que poderia ter optado por virtualmente qualquer coisa. É de causar vertigem a diversidade de temas e campos de investigação com que ele se ocupou entre 1904 e 1909. A Ética protestante foi apenas uma das inúmeras aventuras intelectuais do professor aposentado de economia política. Façamos a conta: neste curto espaço de tempo, além da Ética, ele publica sobre a lógica das ciências culturais (da "objetividade" à crítica das teorias culturais energéticas), sobre a crise política na Rússia czarista, sobre as origens da estrutura agrária alemã (texto apresentado na exposição universal de Saint Louis), sobre as seitas protestantes norte-americanas e, ainda, sobre um tema tão indigesto como a "psicofísica do trabalho industrial". Ao mesmo tempo, Weber escreve réplicas aos primeiros críticos de peso da Ética - os historiadores Karl Fischer e Felix Rachfahl - e assume a direção de dois importantes empreendimentos editoriais: a revista $A r-$ chiv für Sozialwissenschaft und Sozialpolitik e, não muito tempo depois, o Grundriss der Sozialökonomik. É legítimo supor que ele apenas ironizava a si mesmo quando observou, pouco antes de morrer, que "quase todas as ciências devem algo aos diletantes" (Weber, 1988, p. 14.)

Como quer que seja, foi em algum momento deste quinquênio de produção diluviana que Weber se deixou seduzir pela sociologia. Que escrito desta fase melhor se dá a perceber esta "transição"? Friedrich Tenbruck e Wolfgang Mommsen acreditavam que o sociological turn teria se dado entre 1904 e 1906. Acreditamos, de nossa parte, que o momento decisivo deu-se um pouco mais tarde, e que "Relações agrárias na Antiguidade" é o mais eloquente testemunho a esse respeito.

Primorosamente preparada por Jürgen Deininger, no âmbito do gigantesco empreendimento que é a Max Weber Gesamtausgabe (MWG), este volume presta um grande serviço aos que - como Fábio Joly (1999) e Tamara Grigorowitsch (2009) - se deram conta da importância dos estudos de Weber sobre o mundo antigo. Pelo menos desde a preparação de sua tese de livre-docência sobre a História agrária romana, em 1891, ele nunca deixou de se ocupar com a História Antiga, a ponto de podermos dizer que esta, até certo ponto, serviu como uma espécie de laboratório do que viria a ser sua sociologia compreensiva.

O extenso volume traz ainda três estudos de Weber: seu brilhante ensaio "As causas sociais do 
declínio da cultura antiga" e os menos conhecidos e relevantes "A polêmica em torno do caráter da antiga estrutura social alemã na literatura alemã da última década" e "História agrária: Antiguidade". O segundo destes textos havia sido escrito para ser apresentado quando de sua viagem aos Estados Unidos, mas acabou publicado em outubro de 1904 no Anuário de economia politica e estatística. O último foi feito especialmente para a enciclopédia protestante-liberal Die Religion in Geschichte und Gegenwart.

A recepção de "Relações agrárias na Antiguidade" foi prejudicada, no Brasil como alhures inclusive na Alemanha -, pelo fato de se tratar de um estudo situado numa intrincada encruzilhada disciplinar. O texto é na verdade um verbete escrito para o Handwörterbuch der Staatswissenschaften, a convite de Johannes Conrad. Membro destacado da Associação para a Política Social e um dos editores do compêndio, Conrad havia se impressionado com a investigação que Weber fizera sobre os trabalhadores agrícolas do leste do Elba (Bruhns, 2001, pp. 20-21). Foi, portanto, numa publicação capitaneada por economistas políticos que o mais extenso e brilhante trabalho de Weber sobre a Antiguidade veio a lume. Não surpreende que historiadores como Moses Finley e sociólogos como Guy Oakes só tenham-no descoberto muito mais tarde.

Por boas razões, o volume I/6 da MWG é quase que inteiramente dominado por "Relações agrárias". Reproduzem-se as três diferentes ediçôes do ensaio (1897, 1898 e 1909). As poucas diferenças entre as duas primeiras podem ser visualizadas graças a um sistema de edição similar ao da edição da Ética preparada por Antônio Flávio Pierucci. Já a terceira versão, radicalmente alterada e expandida, é reproduzida in extensu (pp. 320-747).

Tal como nos demais volumes da MWG, um dos pontos altos é a introdução do organizador (pp. 1-69). Deininger, que já fora encarregado da edição crítica da História agrária romana (MWG $\mathrm{I} / 2$ ), brindou-nos com uma análise minuciosa e elucidativa sobre o processo de produção do texto, a história de sua recepção e sua conexão com os demais trabalhos de Weber. De fato, a maior tentação a que parecem inclinados os inúmeros editores dos volumes já publicados é a de tentar descobrir indícios do Weber sociólogo nas suas obras "de juventude" - tentação que vitimou o próprio Deininger em MWG I/2. Não é difícil entender o que está por trás desta tentação: busca-se agregar capital simbólico a escritos que, de outra forma, teriam interesse "meramente histórico". Uma arqueologia da sociologia compreensiva supostamente deveria nos levar à sua tese de doutorado Para a história das sociedades comerciais na Idade Média e à História agrária romana. Mas há algo de demasiadamente artificial neste procedimento, nesta aposta. Estes dois livros, ainda que antecipem vários traços que tornaremos a ver no Weber maduro, não oferecem maiores subsídios à tentativa daqueles que, como Wilhelm Hennis, quiseram reconstruir o que seria a sua "questão central".

Tudo muda de figura, porém, quando se trata da terceira e definitiva versão de "Relações agrárias". Escrito no incrível espaço de tempo de quatro meses, entre novembro de 1907 e fevereiro de 1908 - Finley declarou que este fato mais lhe parecia "um milagre saído da Bíblia" -, este ensaio revela um Weber possuído pelo desejo de produzir algo radicalmente novo, o que efetivamente conseguiu, a julgar pela opinião de autores como Perry Anderson, Arnaldo Momigliano, Santo Mazzarino e Luigi Capogrossi Colognesi.

A precoce aposentadoria (consumada em 1903) fez mais bem do que mal ao investigador Max Weber. Seus interesses, como vimos, expandiram-se num ritmo alucinante. A questão do advento do capitalismo moderno, a preocupação em incorporar os "tipos ideais" à análise histórico-social, e, em especial, a disposição em dialogar de forma criativa com a obra de figuras heterodoxas da economia política alemã (Johann Karl Rodbertus e Karl Bücher) deram fôlego e brilho novos ao seu pensamento. Deininger postula que Weber assimilou de Bücher "uma concepção sistematicamente fundamentada, e de caráter especificamente político-econômico sobre a Antiguidade" (p. 12).

Em que medida a terceira edição de "Relações agrárias" revela o surgimento do Weber "sociólogo"? Que o texto tenha sido concluído um ano antes de ele se lançar na organização do primeiro congresso da Sociedade Alemã de Sociologia, 
não é mero detalhe. Mesmo assim, não é o caso de superestimar aqui o peso da rubrica "sociologia", visto que Weber mantinha uma posição bastante pragmática a respeito dos praticantes desta disciplina. Entre os conferencistas do primeiro congresso figuraram o teólogo Ernst Troeltsch, o historiador Eberhard Gothein e o jurista Hermann Kantorowicz. Weber tentara ainda, sem sucesso, convencer o medievalista Georg von Below a participar no evento que, mais tarde, ele próprio ironizou com a expressão salon de refusés. ${ }^{1}$

De um ponto de vista meramente formal, não divergimos substancialmente de Tenbruck (1999) quando entendemos que a sociologia de Weber se caracteriza, de um lado, por densas exposiçóes típico-ideais e, de outro, por seu escopo histórico-universal. Tenbruck enumera os textos em que este estilo weberiano de fazer sociologia (que não é o de Tönnies e muito menos o de Simmel) se manifesta em seu estado mais puro: na "Consideração intermediária", na "Introdução" à Ética econômica das religioes mundiais e na "Nota preliminar" aos Ensaios reunidos de sociologia da religião.

Todavia Tenbruck se esquece que outro texto de Weber, anterior a todos os três mencionados, contém rigorosamente as mesmas características. Referimo-nos à "Introdução" às "Relações agrárias", e que seu autor intitulou "Para uma teoria econômica do mundo estatal (Staatenwelt) da Antiguidade”. Ao longo de 54 páginas (pp. 320-373), Weber se debruça sobre os seguintes temas/problemas: (a) estruturas fundiária e geográfica; (b) importância da guerra para a economia e o desenvolvimento do aparato estatal; (c) dinâmica das relações entre formas de trabalho livre e compulsórias; (d) desenvolvimento da técnica na produção agrícola, bem como do crédito, do comércio e da manufatura; (e) estrutura jurídica e (f) dinâmica do espaço urbano.

Não é preciso ser um expert em Weber para perceber o quanto o problema do capitalismo, pela primeira vez discutido em profundidade na Ética, transborda para um trabalho posterior, que é justamente a terceira versão de "Relações agrárias”. Weber evidentemente não pretende, com isso, fazer uma história do sistema capitalista na longue durée. "A questão", diz ele, "é: a Antiguidade conheceu, numa dimensão relevante do ponto de vista histórico-cultural, uma economia capitalista?" (p. 334).

Weber tinha plena consciência - como seu idolatrado Theodor Mommsen - de que pouco ou nada havia em comum entre o capitalismo antigo e o capitalismo moderno. Nesse sentido, é duplamente revelador o fato de ele ignorar inteiramente, desta vez, a variável "religiāo". Se por capitalista se entende, como quer Weber, qualquer atividade privada cujo objetivo final é a obtenção do lucro, resulta impossível a ideia de que a Antiguidade não conheceu o capitalismo. E vai ainda mais longe. Tal capitalismo não teria sido, no mais fundo de suas entranhas, economicamente, mas sim politicamente determinado (p. 548). Somente a guerra ininterrupta garantia a renovação dos contingentes de mão de obra escrava, e sem escravidão todo o edifício social viria abaixo. A partir do momento em que Roma estabilizou suas fronteiras e as guerras de expansão cessaram, sua sorte estava lançada. Weber conclui que "o capitalismo vivia ali, em última análise, somente do político; ele era, por assim dizer, econômico apenas indiretamente" (p. 715). A aparente ausência de qualquer interferência direta ou indireta dos antigos sistemas religiosos nesta lógica parece indicar que, para Weber, a atividade capitalista no mundo antigo estava condicionada por fatores estritamente "objetivos".

Tais análises não foram feitas por um Weber imaturo, mas pelo mesmo homem que, três anos antes, havia articulado genialmente o advento e a difusão do ascetismo intramundano protestante ao desenvolvimento do capitalismo moderno. Após identificar o que seria a essência deste processo, Weber voltou-se para o capitalismo antigo, sem, contudo, nele desvelar qualquer coisa que se aparentasse a um "espírito".

\section{Nota}

1 Below notabilizar-se-ia por ser um dos mais aguerridos opositores da criação de cátedras de sociologia nas universidades alemãs. Ele empregaria o neologismo cunhado por um antigo professor de Weber em Göttingen, o também historiador Alfred Dove: a sociologia não passaria de um Wortmaskenverleihinstitut. 


\section{BIBLIOGRAFIA}

BRUHNS, Hinnerk. (2001), “À propos de l'histoire ancienne et de l'économie politique chez Max Weber", in Max Weber, Économie et société dans l Antiquité, Paris, La Découverte, pp. 9-59.

GRIGOROWITSCH, Tamara. (2009), "Max Weber e a economia antiga: estratégias metodológicas de reflexão a respeito da economia moderna”. Comunicação apresentada no XIV Congresso Brasileiro de Sociologia.

JOLY, Fábio. (1999), "Capitalismo e burocracia: economia e política nas Relações agrárias na Antigüidade, de Max Weber". Revista de História, 140: 9-22.

LEPSIUS, Mario Rainer. (2005), "Eigenart und Potential des Weber-Paradigmas", in ALBERT, G. Albert; BIENFAIT, A. Bienfait; SIGMUND, S. Sigmund; WENDT, C. Wendt (orgs.), Das Weber-Paradigma. Studien zur Weiterentwicklung von Max Webers Forschungsprogramm. Tübingen, Mohr Siebeck, pp. 32-41.

TENBRUCK, Friedrich. (1999), Das Werk Max

Webers. Tübingen, Mohr Siebeck.

WEBER, Max. (1988), "Vorbemerkung", in , Gesammelte Aufsätze zur Religions-

soziologie, Tübingen, J. C. B. Mohr, pp. 1-16.

SÉRGIO DA MATA

é professor-adjunto do Programa de

Pós-Graduação em História e do

Departamento de História da Universidade

Federal de Ouro Preto - UFOP.

E-mail: <sdmata@gmx.de (sdmata@ichs.ufop.br)>. 